\title{
Pediatric Cranioencephalic Trauma in Senegal: A Consideration of 164 Cases
}

\author{
Ibrahima Tine ${ }^{1}$ Yannick Canton Kessely ${ }^{1}$ August Ndione ${ }^{1}$ Ababacar Mbengue ${ }^{1}$ Adamson Phiri ${ }^{2}$ \\ Abdoul Azize Diop ${ }^{1}$ Sidy Ka ${ }^{3}$ \\ 1 Service de Neurochirurgie, Hôpital principal de Dakar, \\ Dakar, Senegal \\ ${ }^{2}$ Anesthésie-reanimation, Hôpital principal de Dakar, Dakar, Senegal \\ ${ }^{3}$ Service de Pediatrie, Hôpital Principal de Dakar, Dakar, Senegal \\ Indian J Neurosurg 2016;5:10-15. \\ Address for correspondence Yannick Canton Kessely, MD, Service de \\ Neurochirurgie, Hôpital Principal de Dakar, Rte de la Corniche Estate, \\ Dakar, Senegal (e-mail: canton_kessely@yahoo.fr).
}

\begin{abstract}
Keywords

- child

- head trauma

- surgery

The cranioencephalic trauma (CET) is a worldwide public health problem. This study is aims to evaluate the epidemiologic, clinical, paraclinical, and types of treatment of CET in Senegalese children. The study includes children younger than 15 years, victims of CET from January 2008 to December 2012. The series included 164 patients. The average age was 4.96 years, with a sex ratio of 2.72. Patients were transported by unequipped medical ambulance and $65.8 \%$ of the case was discharged within the first 6 hours out of the $79.3 \%$. Two causes of accidents were noted: domestic accident (DA) $56.6 \%$, and road traffic accident (RTA) $29.9 \%$. The initial loss of consciousness (ILC), vomiting, and seizures were reported in $49.5,33.3$, and $17.2 \%$ cases, respectively. The initial Glasgow Coma Scale (GCS) score was between 13 and 15 in 65.2\%, and between 3 and 8 in $16.5 \%$ of the cases. The CT scan revealed that $38.1 \%$ of the injuries affected the bone whereas $34.75 \%$ were normal. Biologically, there was anemia in $51.2 \%$ of the cases and electrolyte imbalance in $16.46 \%$. All patients received medical treatment. Surgery was performed in $21(12.8 \%)$ of the patients. The short-term evaluation results were marked by early mortality in three $(1.29 \%)$ cases. Pediatric CET is dominated by DAs accounting for a significant sequelae. A significant proportion of clinically benign CET patients shows significant lesions on CT scan. Prevention must be the priority.
\end{abstract}

\section{Introduction}

Cranioencephalic trauma (CET) is direct or indirect physical aggression, resulting of diffused or localized signs of brain damage with immediate or delayed onset. CET is a worldwide public health problem. In developed countries, CET is responsible for one-third of deaths among children between 0 and 14 years. ${ }^{1,2}$ Although infectious diseases and malnutrition have not yet been fully eradicated in Africa and Senegal in particular, rapid urbanization has increased CET rates in the pediatric population with severe secondary complications and sometimes disable aftereffect. This survey aims to assess

received

May 28, 2015

accepted

November 18, 2015

published online

February 22, 2016 all circumstances in the case and mostly the clinical, paraclinical, therapeutic, and prognostic aspects of CET on children between 0 to 15 years, and highlight the problems encountered.

\section{Patients and Methods}

This is a retrospective study on CET from January 2008 to December 2012 in the pediatric service of Hopital Principal de Dakar. All children between 30 days and 15 years who were victims of CET were included in this study. All children victims of obstetric trauma and those with incomplete files were excluded.
License terms of India 


\section{Results}

During the study period, 164 patients were treated, a frequency rate of 32.8 patients per year. The average age was 4.96 years (59.59 months) with extremes of 1 and 180 months. The most representative age group was 4 to 7 years at $40.6 \%$, followed by the 30 days to 3 years at $36.6 \%$. There was a male dominance with 120 boys; the sex ratio was of 2.72. Evacuation time was variable (-Table 1) and with unequipped medical ambulance in $79.3 \%$ of cases.

Domestic accidents (DA) were estimated for $56.6 \%$ as causes of trichloroethylene (TCE), and on the other hand, the road traffic accidents (RTAs) ranked 29.9\%. The circumstances of occurrence were diversified according to age (-Table 2 ).

Fall from height due to DA was estimated at 92.5\%, fall from arms of bearer estimated at $4.3 \%$, fall from bed estimated at $1.1 \%$, and fall from the patient's own height estimated at $2.2 \%$. The 1 month to the 3 years age group was the touchiest one. We recruited 49 RTA victims, of whom $77.6 \%$ were pedestrians and $21.05 \%$ of these had severe CET, and the rest were passengers accounting for $27.3 \%$.

Initial loss of consciousness (ILC) (49.5\%) was the predominated symptoms, followed by vomiting (33.3\%) and, lastly, seizures (17.2\%); 37 were put into CET observations due to lack of accompanying signs and symptoms. In $27 \%$ of the patients, the period of ILC was greater than 5 minutes and less in $12 \%$ of the cases. Two patients had repetitive seizures. There were 39 cases with different episodes of vomiting, fewer than 3 cases in 24 hours, 10 cases had more than three episodes of vomiting in 24 hours, and only one case of vomiting exceeded 24 hours period.

During the admission, $65.2 \%$ or 107 patients had a GCS between 13 and $15,17.7 \%$ between 9 and 12 , and $16.5 \%$ a score less than or equal to 8. During clinical examination, $44.5 \%$ were found to have reactive pupils. Cephalic examination revealed that a predominance of scalp wounds (25.9\%), followed by cephalohematoma (17.6\%) and edema face (15.1\%). Neurologic motor deficit was found in $6.7 \%$ of the cases, and troubles in meningeal and higher-center functions in $1.2 \%$ of cases. In our

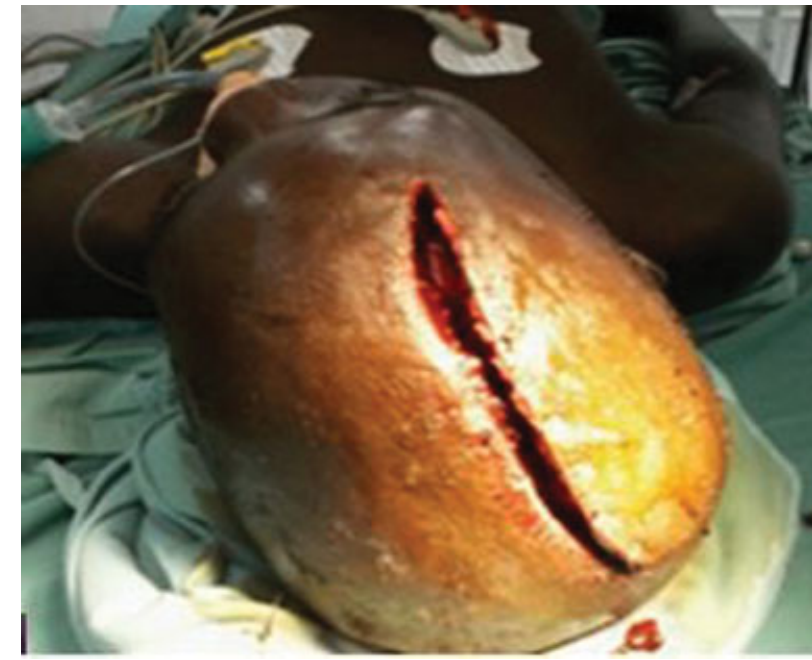

Fig. 1 Scourge of the hairy leather.

sample we found 6 cases of skull fractures, 25 of otorrhagia, 19 of epistaxis, and 3 of hemotympanum. Furthermore, 59 associated with lesions were identified: 27 were maxillofacials, 24 locomotors, 4 abdominales, 3 thoracics, and 1 spinal (-Fig. 1 ).

A radiography was performed in $20(12.2 \%)$ patients of skull, $30(18.3 \%)$ of the cervical spine, $23.2 \%$ of limbs, and $29.3 \%$ of chest. In addition, $90 \%$ of the X-rays reports were without any lesion seen or any fracture found, one dislocation, three mixed lesions, one depressed fracture, and one spinal injury. Abdominal ultrasound was performed on $7.3 \%$ of the patients and cerebral CT scan on $97 \%$. With the CT scans, bone lesions were most common (52, 4\%), and normal in 57 (34.76\%) patients (-Table 3).

Out of the 86 children with bone lesions, the majority were clinically considered CET minor case. We compiled 109 bones lesions of which 70 were at the vault and 39 at the base. The fracture line was simple in 47 (60.3\%) cases and comminuted in 15; the fractures were depressed in 15 cases and we found only 1 flap-type fracture. The fracture sites were more frequently

Table 1 Time evacuation

\begin{tabular}{|l|l|l|l|l|l|l|}
\hline Duration & $\mathbf{1} \mathbf{h}$ & $\mathbf{1 - 6} \mathbf{h}$ & $\mathbf{6 - 2 4} \mathbf{h}$ & $\mathbf{2 4 - 4 8} \mathbf{h}$ & $>\mathbf{4 8} \mathbf{h}$ & Nonresponse \\
\hline No. & $25(15.2 \%)$ & $83(50.6 \%)$ & $17(10.4 \%)$ & $\begin{array}{l}8 \\
(4.9 \%)\end{array}$ & $\begin{array}{l}6 \\
(3.7 \%)\end{array}$ & $\begin{array}{l}25 \\
15.2 \%)\end{array}$ \\
\hline
\end{tabular}

Table 2 Circumstance occurred according to the age

\begin{tabular}{|c|c|c|c|c|c|}
\hline & $1 \mathrm{mo}-3 \mathrm{y}$ & $4-7 y$ & $8-11 y$ & $12-15 y$ & No answer \\
\hline RTA & 8 & 28 & 6 & 6 & 1 \\
\hline DA & 42 & 33 & 13 & 5 & 0 \\
\hline PA & 5 & 3 & 4 & 0 & 0 \\
\hline PAb & 4 & 1 & 1 & 0 & 0 \\
\hline Other & 1 & 1 & 0 & 1 & 1 \\
\hline Total & 60 & 66 & 24 & 12 & 2 \\
\hline
\end{tabular}

Abbreviations: DA, domestic accident; PA, playful accident; PAb, physical abuse; RTA, road traffic accidents. 
Table 3 CT scan results of craniocerebral lesions

\begin{tabular}{|l|l|}
\hline Primary lesions & Number quote \\
\hline Lesions bone & 86 \\
\hline Hematoma & 26 \\
\hline Hemorrhage meningeal & 6 \\
\hline Hemorrhage intraventricular & 1 \\
\hline Bruising & 32 \\
\hline Ischemia & 0 \\
\hline Lesions diffuse axonal & 14 \\
\hline Cervical spine & 4 \\
\hline Hygroma & 0 \\
\hline Normal & 57 \\
\hline
\end{tabular}

Abbreviation: $\mathrm{CT}$, computer tomography.

parietal (43\%) than the frontal (27\%), temporal (23\%), and finally occipital $7 \%$. At level of the skull base, the fracture line was predominantly simple in $87.5 \%$ cases and comminuted in $12.5 \%$ cases. At the level of fracture's site, the anterior floor was much sought $(63.5 \%)$, followed by the posterior floor (25\%) and finally the middle level (11.4\%). The imagery of associated injuries found 10 fractures of the limbs, 4 visceral thoracic lesions, and 3 abdominal visceral lesions.

The CT scan revealed 28 hematomas of which 13 were subdural acute, 12 intraparenchymal, and 3 epidural. Hematomas were parietal (46.9\%), frontal (34.4\%), and temporal (18.8\%). The three epidural hematoma patients had no vigilance disorders during the admission. In the case of subdural hematomas, nine were clinically classified as benign CET, one was moderate, and three severe. Among the 12 intraparenchymal hematomas, 7 were benign CET, 3 moderate, and 2 severe. Cerebral edema was diagnosed in 23 patients and cerebral herniation in 3 others (-Fig. 2).

Anemia was diagnosed in $84(51.2 \%)$ patients, hyponatremia in 15 , hyperkalemia in 7 , hypokalemia in 3 , and a
Table 4 Medium- and long-term evolution

\begin{tabular}{|l|l|l|}
\hline $\begin{array}{l}\text { Evolution means, } \\
\text { long-term }>\mathbf{1} \mathbf{~ m o}\end{array}$ & $\begin{array}{l}\text { No. of } \\
\text { citations }\end{array}$ & $\begin{array}{l}\text { Frequencies } \\
(\%)\end{array}$ \\
\hline Epilepsy & 2 & 1.2 \\
\hline Infection & 3 & 1.8 \\
\hline Motor deficit & 10 & 6.0 \\
\hline Cognitive impairment & 1 & 0.6 \\
\hline Vestibular sequelae & 1 & 0.6 \\
\hline Cerebellar sequelae & 1 & 0.6 \\
\hline $\begin{array}{l}\text { Vegetative state } \\
\text { (relational) }\end{array}$ & 2 & 1.2 \\
\hline Good & 19 & 11.4 \\
\hline Unanswerable & 128 & 76.7 \\
\hline Total citations & 167 & 100 \\
\hline
\end{tabular}

hypernatremia in 2. Hyperglycemia was found in 50 patients at admission and hypoglycemia in 12 .

One hundred and thirty-two patients did not receive any emergency. Analgesics were administered in 36.3\%, the antibiotics in $21.6 \%$, eye drops and anticonvulsants in $11 \%$, and corticoid and oxygen therapies in 6\%. Blood transfusion was administered in 20 patients and osmotherapy was done on 12 patients. Surgical treatment consisted of complete wound debridement and suture in 13 patients, elevation of depressed fracture in 5 of the 15 identified cases, and hematoma evacuation in 3 of the 26 identified cases.

We deplored the deaths of $3(1.83 \%)$ patients on day 1 due to trauma. One day after admission, we identified six patients with motor deficit, three with increased intracranial pressure, and three who had seizures. The state of alertness was conserved in $62.8 \%$; $4.3 \%$ had a GCS between 9 and 12 , whereas $26.8 \%$ had a score less than or equal to 8 . A week after admission, we identified 11 patients with motor deficits, 4 with increased intracranial pressure, and 2 with convulsions.
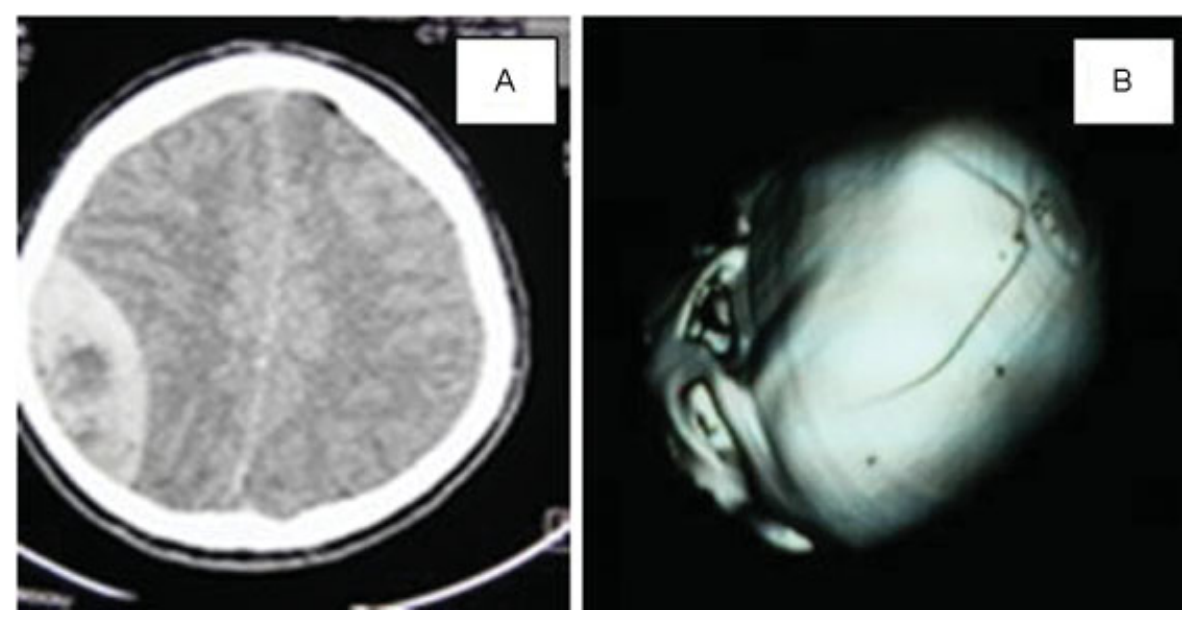

Fig. 2 (A) CT scan showing an epidural hematoma parietal right. (B) A 3D reconstruction showing a left frontoparietal fracture. 
Alertness was preserved in $36.6 \%$ of the patients, and $4.9 \%$ had a severe drop in their state of alertness. The evolution beyond a month is reported in - Table 4.

\section{Discussion}

The CET affects 100,000 to 150,000 children per year of whom 10 to $15 \%$ die or suffer permanent brain damage. ${ }^{3}$ Half of the CET patients in the United Kingdom are younger than 16 years and one-third in the United State are children between 0 and 14 years. ${ }^{4}$ In Scotland children between 0 and 14 years represent $50 \%$ of admissions in emergency departments for CET. ${ }^{5}$ The male predominance was noted with a sex ratio of 2.72. Per Langlois et al, ${ }^{4}$ boys are twice as much affected as girls. Similarly gender favored male population in Taiwan: $1.69 / 1 .^{6}$ This predominance might be explained by the fact that the boy has a great freedom and therefore a large mobility, which exposes him to the trauma. We report a high percentage of unequipped and unsafe patient transportation $(79.3 \%)$ tied in to the lack of organization of management of emergencies. Only $15.2 \%$ of patients were admitted within less than 1 hour.

We found a predominance of DAs (56.6\%), and it has also been reported by various authors. ${ }^{7,8}$ As per Kim et al, ${ }^{9}$ it is a function of age: the older the patient, the more unlikely that DAs are the cause, and the more likely that RTA and sports accidents are the causes. In contrast, in Taiwan, more than $70 \%$ of injuries are caused by RTA that is the main cause of death in the 0 to 14 years group of age, ${ }^{10}$ so is the case reported by Kraus et al. ${ }^{11}$ Per Alexiou et al, ${ }^{12}$ among children younger than 2 years, child abuse remains the major cause of trauma. We found that DAs are essentially dominated by fall from height (92.5\%). Like Adirim et $\mathrm{al}^{13}$ Sharples et $\mathrm{al}^{14}$ reported a rate of RTA of $76 \%$ involving $77.6 \%$ pedestrians.

Headache was the main reason for seeking medical help. The dominance of ILC noted (61.6\%) is in line with the study of the Korean team that pegged the rate of loss of consciousness at $97.4 \%$, vomiting in $80.2 \%$, and dizziness in $58.2 \%{ }^{9}$ Posttraumatic vomiting is defined as vomiting that occurs within 72 hours of head trauma not attributed to any other cause. ${ }^{15}$ We report a rate of vomiting of $41.5 \%$ much higher than that reported by Brown et $\mathrm{al}^{15}{ }^{15}$ which was at $15.8 \%$ and that of other publications, which varies from 10 to $17 \%{ }^{16}$ Posttraumatic vomiting has been a subject of several studies. The pathophysiology is subject of controversy. Occipital trauma will stimulate the vomiting center, ${ }^{17}$ and this has not been confirmed by other. ${ }^{16}$ Other intrinsic factors such as a family migraine predisposing certain people have been incriminated. ${ }^{18}$ The association of vomiting and brain lesion on the CT scan has also been studied with different results: 40 to $45 \%$ of cases $^{19}$ and $13 \%$ of cases. $^{20}$ In children, the value of vomiting as CT of the brain scan output indicator is not clear. ${ }^{16}$

We have noted in this study that the majority (62.5\%) of CET cases were minor in accordance with the literature. ${ }^{21,22}$ This would also explain the high rate of patients without neurologic deficit. The associated injuries were managed in collegial manner.

The CT scans of the brain were performed according to the classification of Masters et al. ${ }^{23}$ Out of 107 patients classified as benign CET, 65 (39.6\%) had an abnormal result, including $3(1.83 \%)$ requiring emergency surgical care. Osmond et $\mathrm{al}^{24}$ found in a study of 3,866 children with benign CET that the cerebral CT scan was not required, yet this examination revealed brain injury in 159 (4.1\%), including $24(0.6 \%)$ who benefited from neurosurgery. At the Canadian pediatric emergency department, the use of brain scans for minor CET rose from 15\% in 1995 to $53 \%$ in $2005^{24}$. Despite this growth, several intracranial hematomas are not diagnosed at the first visit. Thus there is controversy concerning performance of brain scans in children who are victims of minor $\mathrm{CET}^{24}$; different criteria not unanimously agreed upon were validated. The scanner in the first hour is recommended if there are three or more episodes of vomiting. According to the Canadian Assessment of Tomography for Childhood Head injury (CATCH), ${ }^{24}$ highrisk patients requiring a CT scan of the brain are those who have a GCS of lower than 15 after 2 hours of trauma and in whom there is suspicion of a fracture of the skull, with growing aggravation of headache and irritability. Concerning unnoticed hematomas, as has been suggested by Ciurea et $\mathrm{al}^{25}$ there must be more than $100 \mathrm{~mL}$ of blood in epidural space before any neurologic manifestation, the total blood volume in children being 550 to $600 \mathrm{~mL}$ at the age of 3 months, 700 to $800 \mathrm{~mL}$ at 1 year, 850 to $950 \mathrm{~mL}$ at 2 years, 1,300 to $1,400 \mathrm{~mL}$ at 5 years and 3,500 to $4,000 \mathrm{~mL}$ at 15 years. Therefore, children who have epidural hematoma may present with acute anemia, hypotension, or hypovolemic shock. The use of the CT scan in our study was $97 \%$ against $22.2 \%$ in the Korean study. ${ }^{9}$ This low rate is related to the need for appropriate use of CT scan of the brain, specifically in pediatric patients who are radiosensitive. ${ }^{26}$ According to a recent estimate, the risk of developing cancer after performing a brain scan depends on the child's age and ranges from $1 / 2,000$ to $1 / 5,000 .^{27}$

We found 13 subdural hematomas versus 3 (1.83\%) epidural ones because the acute epidural hematoma in the pediatric population is rare. According Ciuera et al, ${ }^{25}$ its frequency is lower than 3\% of all CET and is uncommon in patients younger than 3 years as the dura mater is adherent to the internal layer. The most encountered lesion was secondary cerebral edema. We also found that patients with minor cranial trauma had the most lesions on the CT scan: $61.6 \%$ of bone lesions, $69.23 \%$ of hematoma, and contusions $65.6 \%$. This has also been noted by Ibrahim et $\mathrm{al}^{28}$ that out of $46 \%$ of children with primary intracranial lesion on CT, $30 \%$ had no skull fracture, $8 \%$ did not have a skull fracture or soft tissue injury, and the presence of external signs of trauma does not always correlate with intracranial lesions.

We have listed anemia in 84 patients at admission; this corresponds to deficiency anemia and blood loss (hematoma, bleeding of associated lesions). Anemia was not a bad prognostic factor in this study. Hyperglycemia was noted in one of our patients who died. According Zygun et $\mathrm{al}^{29}$ hyperglycemia reflects a severe brain injury and is a factor of 
poor prognosis as it worsens cerebral lactic acidosis. We noted at admission a hyperglycemia in 50 (30.5\%) patients, and listed as $16.5 \%$ of patients with severe trauma. One day after the trauma, we had $26.8 \%$ of patients who had a GCS less than 8 ; this figure is similar to that of patients who had hyperglycemia on admission (30.5\%). Sharma et $\mathrm{al}^{30}$ reported that perioperative blood glucose ( $\geq 200 \mathrm{mg} / \mathrm{dL}$ ) in $45 \%$ of children with severe cranial trauma significantly associated with a lower age 4 years, with a GCS lower than 8 and in the presence of multiple lesions. Per Cochran et $\mathrm{al}^{31}{ }^{31}$ higher blood glucose levels equal to or greater than $300 \mathrm{mg} / \mathrm{dL}$ at admission is uniformly associated with death.

Although the growing use of CT scan of the brain increases the cost of health and exposes patients to ionizing radiation. ${ }^{32}$ We do not yet have the possibilities of using the biological markers of brain injury, including such as S100B protein, high in 6 hours of head trauma, ${ }^{33}$ which can assist in the selection of patients requiring CT scan of the brain, ${ }^{30}$ but it is unreliable when there is multiple traumatism and NSE (neuron-specific enolase) predictive of the presence of an intracranial lesion beyond $15.3 \mathrm{ng} / \mathrm{dL}^{34}$ In their study, Dunning at $\mathrm{al}^{35}$ reported that a GCS inferior to 9 is associated with a coagulopathy (poor prognosis) in $81 \%$ of children. We did not observe this during the study, but investigations later in this direction are necessary.

The $1.83 \%$ death rate is higher than that reported by Kim et $\mathrm{al}^{9}{ }^{9}$ which was $0.06 \%$. The mechanism of death in our study was a fall from first floor, falling from the arms of a carrier and one RTA. Two of them presented with ear hemorrhage and a fracture of the femur. Bleeding internally from a ruptured spleen was diagnosed in the latter. A child was brought in died, and another died after intubation and sedation. The last one died after the use of vasopressors and osmotherapy. Overall evolution was good in most cases with complete recovery without sequelae. Complications were noted in $8.9 \%$. This low rate of complications is associated with good compliance of the skull of the child, which is elastic and can absorb the impact and protect the brain.

In our series $80.9 \%$ of patients did not receive emergency first aid; this is correlated with the rate of transport unsafe that was $79.3 \%$. We made use of corticosteroids in $6 \%$ of patients primarily due to increased intracranial pressure with a favorable results, but according Hu et al, ${ }^{10}$ the current research does not show the beneficial effect of the use corticosteroids in patients with head trauma. A large prospective multicenter study also showed an increasing mortality among patients with acute traumatic brain injury who received treatment with corticosteroids. ${ }^{7}$

An increase in the deficit is recorded and can be explained by the improvement of the vigilance of comatose children who allows us to objectify difficult motor deficits noted in an unconscious patient.

\section{Conclusion}

In children from 0 to 15 years, the boys are twice much susceptible to be a victim of CET caused by DAs than girls. More than one-third of CT scans done were normal; most of the cerebral lesions are detected by CT scan devices on patients with minor CET, but surgical treatment is not always required. An improvement should be made to equip and make patient transportation safer and the selection of patients requiring a CT of the brain scan (using brain injury markers). Moreover, prevention should be the first ever concern.

Those DAs happen to be the first cause and are essentially due to fall from height especially from a terrace or from stairs. It is always necessary to mention the paradox between the importance of CT lesions and the benignity of the clinic board. Comparison has shown that a child tolerates the TCE more than an adult.

\section{Conflict of Interest}

None.

\section{References}

1 Sharples PM, Storey A, Aynsley-Green A, Eyre JA. Avoidable factors contributing to death of children with head injury. BMJ 1990;300(6717):87-91

2 National Center for Injury Prevention and Control. injury statistics query and reporting system. http://www.cdc.gov/ [cited 2014 Oct 28 ] http://webappa.cdc.gov/sasweb/ncipc/ leadcaus10.html

3 Adelson PD. Hypothermia following pediatric traumatic brain injury. J Neurotrauma 2009;26(3):429-436

4 Langlois JA, Rutland-Brown W, Wald MM. The epidemiology and impact of traumatic brain injury: a brief overview. J Head Trauma Rehabil 2006;21(5):375-378

5 Jennett B. Epidemiology of head injury. Arch Dis Child 1998; 78(5):403-406

6 Tsai WC, Chiu WT, Chiou HY, Choy CS, Hung CC, Tsai SH. Pediatric traumatic brain injuries in Taiwan: an 8-year study. J Clin Neurosci 2004;11(2):126-129

7 Shudy M, de Almeida ML, Ly S, et al. Impact of pediatric critical illness and injury on families: a systematic literature review. Pediatrics 2006;118(Suppl 3):S203-S218

8 Hawkins ER, Brice JH, Overby BA. Welcome to the world: findings from an emergency medical services pediatric injury prevention program. Pediatr Emerg Care 2007;23(11):790-795

9 Kim HB, Kim K, Kwak YH, et al. Epidemiology of traumatic head injury in Korean children. J Korean Med Sci 2012;27(4): 437-442

$10 \mathrm{Hu}$ CF, Fan HC, Chang CF, Chen SJ. Current approaches to the treatment of head injury in children. Pediatr Neonatol 2013; 54(2):73-81

11 Kraus JF, Fife D, Cox P, Ramstein K, Conroy C. Incidence, severity, and external causes of pediatric brain injury. Am J Dis Child 1986; 140(7):687-693

12 Alexiou GA, Sfakianos G, Prodromou N. Pediatric head trauma. J Emerg Trauma Shock 2011;4(3):403-408

13 Adirim TA, Wright JL, Lee E, Lomax TA, Chamberlain JM. Injury surveillance in a pediatric emergency department. Am J Emerg Med 1999;17(6):499-503

14 Sharples PM, Storey A, Aynsley-Green A, Eyre JA. Causes of fatal accidents impliquant childhood head injury in Northern Region. BMJ 1979;301:1193-1197

15 Brown FD, Brown J, Beattie TF. Why do children vomit after minor head injury? J Accid Emerg Med 2000;17(4):268-271

16 Ando S, Otani M, Moritake K. Clinical analysis of post-traumatic vomiting. Acta Neurochir (Wien) 1992;119(1-4):97-100 
17 Lawes INC. The origin of the vomiting response: a neuroanatomical hypothesis. Can J Physiol Pharmacol 1990;68(2):254-259

18 Jan MM, Camfield PR, Gordon K, Camfield CS. Vomiting after mild head injury. J Pediatr 1997;130:134-137

19 Abdul Rahman YS, Al Den AS, Maull KI. Prospective study of validity of neurologic signs in predicting positive cranial computed tomography following minor head trauma. Prehosp Disaster Med 2010;25(1):59-62

20 Saadat S, Ghodsi SM, Naieni KH, et al. Prediction of intracranial computed tomography findings in patients with minor head injury by using logistic regression. J Neurosurg 2009;111(4):688-694

21 National Center for Injury Prevention and Control Traumatic brain injury in the United States: (2014). Assessing outcomes in children. http://www.cdc.gov/traumaticbraininjury/ assessing outcomes_in_children. html

22 Williamson LM, Morrison A, Stone DH. Trends in head injury mortality among 0-14 year olds in Scotland (1986-95). J Epidemiol Community Health 2002;56(4):285-288

23 Masters SJ, McClean PM, Arcarese JS, et al. Skull x-ray examinations after head trauma. Recommendations by a multidisciplinary panel and validation study. $\mathrm{N}$ Engl J Med 1987;316(2):84-91

24 Master SJ, McClean PM, Arcarese JS, et al; Pediatric Emergency Research Canada (PERC) Head Injury Study Group. CATCH: a clinical decision rule for the use of computed tomography in children with minor head injury. CMAJ 2010;182(4):341-348

25 Ciurea AV, Gorgan MR, Tascu A, Sandu AM, Rizea RE. Traumatic brain injury in infants and toddlers, $0-3$ years old. J Med Life 2011;4(3):234-243

26 King MA, Kanal KM, Relyea-Chew A, Bittles M, Vavilala MS, Hollingworth W. Radiation exposure from pediatric head CT: a bi-institutional study. Pediatr Radiol 2009;39(10):1059-1065
27 Brenner DJ, Hall EJ. Computed tomography-an increasing source of radiation exposure. N Engl J Med 2007;357(22): $2277-2284$

28 Ibrahim NG, Wood J, Margulies SS, Christian CW. Influence of age and fall type on head injuries in infants and toddlers. Int J Dev Neurosci 2012;30(3):201-206

29 Zygun DA, Steiner LA, Johnston AJ, et al. Hyperglycemia and brain tissue pH after traumatic brain injury. Neurosurgery 2004;55(4): 877-881, discussion 882

30 Sharma D, Jelacic J, Chennuri R, Chaiwat O, Chandler W, Vavilala MS. Incidence and risk factors for perioperative hyperglycemia in children with traumatic brain injury. Anesth Analg 2009;108(1): 81-89

31 Cochran A, Scaife ER, Hansen KW, Downey EC. Hyperglycemia and outcomes from pediatric traumatic brain injury. J Trauma 2003;55(6):1035-1038

32 Hall P, Adami HO, Trichopoulos D, et al. Effect of low doses of ionising radiation in infancy on cognitive function in adulthood: Swedish population based cohort study. BMJ 2004;328(7430):19

33 Laupacis A, Sekar N, Stiell IG. Clinical prediction rules. A review and suggested modifications of methodological standards. JAMA 1997;277(6):488-494

34 Fridriksson T, Kini N, Walsh-Kelly C, Hennes H. Serum neuronspecific enolase as a predictor of intracranial lesions in children with head trauma: a pilot study. Acad Emerg Med 2000;7(7): 816-820

35 Dunning J, Daly JP, Lomas J-P, Lecky F, Batchelor J, Mackway-Jones $\mathrm{K}$; Children's head injury algorithm for the prediction of important clinical events study group. Derivation of the children's head injury algorithm for the prediction of important clinical events decision rule for head injury in children. Arch Dis Child 2006;91(11):885-891 